\section{A comparison of two methods of measuring conditioned taste aversions}

\author{
WILLIAN DRAGOIN*, GERALD E. McCLEARY, and PATRICIA McCLEARY \\ Auburn University, Auburn, Alabama 36830
}

Two methods of measuring conditioned taste aversions were compared. Following adaptation to a daily 10-min water drinking schedule, rats were made ill with an injection of cyclophosphamide after presentation of a novel-tasting fluid. Three days after this treatment, Ss were tested by (1) measuring the amount of the novel fluid consumed on the continuing 10-min access schedule or (2) measuring their preference between plain water and the novel fluid. When the drinking behavior of the conditioned animals was compared with that of appropriate controls, the preference method proved to be the more sensitive.

Rats made ill following the ingestion of a novel-tasting substance will reject that substance when it is encountered again. This phenomenon is called conditioned taste aversion and has recently been the subject of much research, which has been reviewed by Revusky and Garcia (1970). The research indicates that these aversions result from the specific pairing of gustatory and/or olfactory cues with internal visceral malaise, and that they can be established even when the induced illness follows the ingestion of the novel substance by as much as $7 \mathrm{~h}$ (Smith \& Roll, 1967; Revusky, 1968).

Some studies of conditioned taste aversions (e.g., Kral, 1970) involve adapting the animal to a water-drinking schedule and then presenting him with a distinctively flavored fluid. Following the consumption of this flavored fluid, the animal is made ill, typically by a drug injection or exposure to $\mathrm{X}$-irradiation, and returned to his water-consumption schedule. Several days following this treatment, the $\mathbf{S}$ is again given access to the flavored fluid, but usually drinks considerably less than he did upon the initial exposure. This can be termed a "forced-drinking" method, since the animal adapted to such a drinking schedule (typically $10 \mathrm{~min}$ a day access to water) is considerably deprived and is highly motivated to drink the novel-tasting fluid, even though it has been conditionally paired with induced illness. Some studies (e.g., Bradley \& Mistretta, 1971), have tested the $S$ by giving him access to the novel fluid that has been paired with illness and access to water, with relative preference for the two substances being the dependent variable. The latter method (termed "preference-drinking") would appear to have an advantage over the

*Reprint requests may be sent to $W$. $B$. Dragoin, Department of Psychology, Auburn University, Auburn, Alabama 36830 . forced-drinking method in that the animals are not deprived during the test session. The purpose of the present investigation was to compare these two methods of measuring taste aversions.

\section{METHOD}

\section{Subjects}

The Ss were 28 rats (Sprague-Dawley albino), 90-120 days old at the beginning of the experiment, and were housed and tested in $12 \times 10 \times 6$ in. high plastic cages. The Ss had access to Purina Laboratory Rat Chow ad lib.

\section{Procedure}

The animals were assigned randomly to four treatment groups $(\mathrm{N}=7)$, with two groups designated as forced drinking and two as preference drinking.

All Ss were adapted to a $10-\mathrm{min} / \mathrm{day}$ watering schedule for 6 days. For the forced-drinking group, a 100-ml bottle with stainless steel drinking tube was placed in each cage for $10 \mathrm{~min}$, removed, and the amount consumed measured with a graduated cylinder. The preference-drinking group was offered two bottles for $10 \mathrm{~min}$ each day, one empty and one containing tap water. To avoid a position preference in the groups, the placement of the full and empty bottles in the cages was varied in the following manner: RRLRLL. On treatment day, all animals were given access to a novel-tasting fluid $(.02 \%$ saccharin solution) for $10 \mathrm{~min}$, and the amount consumed was recorded. The forced-drinking group received one bottle filled with the saccharin solution and the preference group received two bottles with this fluid. Approximately $30 \mathrm{~min}$ following the removal of the bottles from the cages, one of the forced-drinking groups and one of the preference-drinking groups were given an intraperitoneal injection of cyclophosphamide (CytoxanR, Mead-Johnson Laboratories, Evansville, Indiana), a nausea-inducing agent. The dosage, $66 \mathrm{mg} / \mathrm{kg}$ of S's body weight, has been shown to be effective in conditioning taste aversions (Dragoin, 1971). The remaining forced-drinking and preference-drinking groups received comparable injections of isotonic saline. Following treatment, the animals were returned to the baseline drinking schedule for 2 days. On the third day following treatment, the Ss were again offered the saccharin solution in the following manner: the forced-drinking group was simply given access to the fluid in a single bottle for $10 \mathrm{~min}$ and the preference-drinking group was provided with two bottles, one containing the saccharin solution and one containing water. The access time for the preference-drinking group was $12 \mathrm{~h}$. These tests were repeated two additional times at intervals of 3 days with the 10-min baseline continued on intervening days. A total of three tests was made for all groups.

\section{RESULTS AND DISCUSSION}

The results of the three test trials for the forced-drinking groups are shown in Fig. 1. A two-way analysis of variance revealed that the average amount consumed by the saline and drug groups did not differ significantly $(F=1.8 ; \mathrm{df}=1 / 12 ; \mathrm{p}>.20)$, although the difference on the first test approached significance $(t=2.01$; $\mathrm{df}=12 ; \mathrm{p}>.10<.05$ ). The Trials by Conditions interaction was significant $(F=3.7 ; \quad d f=2 / 24 ; \quad p<.05)$, reflecting an increase in drinking by the drug group and a decrease by the saline group on the last two tests.

The results of the preference-drinking measure are more clear-cut. Figure 2 depicts the average amount of liquid consumed in the 12-h test and illustrates the average amount of saccharin solution or water drunk by the saline and drug groups. Under these conditions, amount of saccharin solution drunk by the drug-injected animals is markedly less than that drunk by the saline

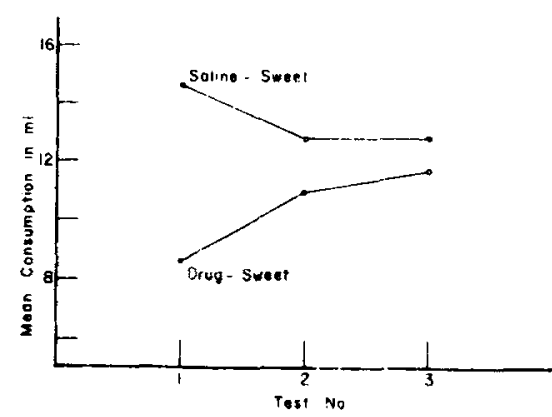

Fig. 1. Average amount of saccharin solution (sweet) consumed by drug and saline sroups on three tests. 


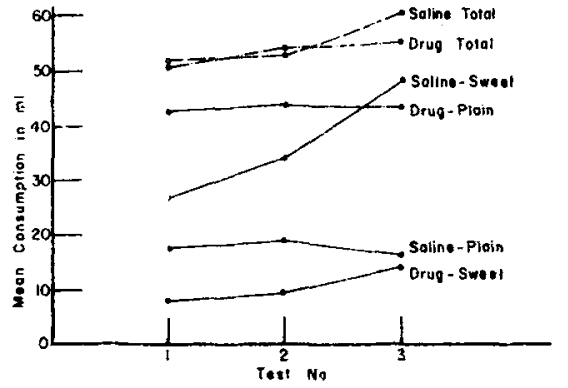

Fig. 2. Average amount of liquid, saccharin solution (sweet) and water (plain), consumed by drug and saline groups on three tests.

controls $\quad(F=17.33 ; \quad d f=1 / 12$ $\mathrm{p}<.005)$. Indeed, the saline-injected animals have a preference for the accharin solution. These differences are maintained on all three tests. As is seen, the forced-drinking method results are nonsignificant and those generated by the preference-drinking method are highly significant.

The preference-drinking method is a much more sensitive measure of learned aversions than is the forced-drinking method. In the latter, the deprivation conditions inherent in the method result in increased variability in drinking for the conditioned animals. That is, even though the saccharin solution is aversive, some Ss do drink because of their great thirst. When $\mathbf{N}$ is small, as in the present study, the method may produce ambiguous results. The preference-drinking methodology, by removing the high-motivation variable, results in more salient differences between conditioned animals and their controls. Researchers studying taste aversions should consider the preference-testing measure, particularly if the effects of a nonpowerful variable are being investigated or $\mathrm{N}$ is small.

\section{REFERENCES}

BRADLEY, R. M., \& MISTRETTA, C. M.
Intravascular taste in rats as demonstrated by conditioned aversion to sodium saccharin. Joumal of Comparative \& Physiological Psychology, 1971, 75 . 186-189.

DRAGOIN, W. B. Conditioning and extinction of taste aversions with variations in intensity of the CS and UCS in two strains of rats. Psychonomic Science, 1971, 22, 303-305.

KRAL, P. Interpolation of electroconvulsive shock during CS-US interval as an impediment to the conditioning of taste aversion. Psychonomic Science, 1970, 19, 36-37.

REVUSKY, S. H, Aversion to sucrose produced by contingent $X$-irradiation: Temporal and dosage parameters. Journal of Comparative \& Physiological Psychology, 1968, 65, 17-22.

REVUSKY, S. H:, \& GARCIA, J. Learned associations over long delays. In $G$. Bower (Ed.), The psychology of learning and motivation: Advances in research and theory. Vol. 4. New York: Academic Press, 1970.

SMITH, J. C., \& ROLL, D. L. Trace conditioning with $\mathrm{X}$-rays as the aversive stimulus. Psychonomic Science, 1967, 9, 11-12. 